\title{
An Exploratory Study on how to Improve Bedside Change-of -Shift Process: Evidence from One Hospital Using Technology to Support Verbal Reporting.
}

\author{
Kaushik Ghosh \\ Lamar University \\ kghosh@lamar.edu \\ Patricia Morrell \\ CHRISTUS-St. Elizabeth \\ patricia.morrell@christushealth.org
}

\author{
Eileen Curl \\ Lamar University \\ curled@lamar.edu
}

\author{
Mary Goodwin \\ CHRISTUS-St. Elizabeth \\ m.goodwin@christushealth.org \\ Paul Guidroz \\ CHRISTUS-St. Elizabeth \\ paul.guidroz@christushealth.org
}

\begin{abstract}
Change-of-shift report, often referred to as patient handoff in the inpatient setting involves exchange of accurate and critical information between providers to ensure continuity of patient care. Inefficient communication significantly contributes to medical errors, affecting patient safety, and care quality. The current exploratory study was conducted to understand the issues associated with change-of-shift reporting that occurs throughout one hospital in its various nursing units. Nurses participating in the study were assigned a simulated patient case to develop a shift report to transfer to the incoming nurse. After completing the report, each nurse was interviewed using open-ended questions. Based on qualitative analysis of data obtained from sixteen one-on-one nurse interviews, ten themes were identified. The themes highlighted issues that posed coordination challenges for nurses, impeded nurse workflow, and underscored deficiencies in the bedside reporting process followed at the hospital. Recommendations are discussed on how to overcome these challenges.
\end{abstract}

\section{Introduction}

In hospital settings, nurses begin each shift by participating in handoffs or a change-of-shift report [19]. The primary purpose of a nurse handoff is to communicate from nurse-to-nurse, accurate and critical information required for continuity of patient care [2, 3 , 18]. Communication failures compromise patient treatment, care quality, and safety $[6,20]$. It also leads to medical errors, the third leading cause of deaths in the United States [17]. Further, inefficient shift reporting practices may reduce time spent by nurses on direct patient care and increase the cost of care [6].
There are several ways to conduct change-of-shift report or handoff; verbal, tape-recorded, written, telephonic, and bedside nurse-to-nurse report or combinations of these methods. There are advantages and disadvantages ascribed to all methods. Some scholars view methods that use an Electronic Medical Record (EMR) as more streamlined, cost effective, and easily standardized [1, 11, 18]. Although an accurate change-of-shift report is critical to ensuring knowledge transfer from nurse-to-nurse, handoffs often lack standardization, are unstructured and communicated haphazardly. Consequently, information transmitted between nurses varies considerably in quality and content, leading to risk of communication failures.

Bedside nurse-to-nurse change-of-shift report, which is the context of this study, involves face-to-face interactions between the on duty (offgoing) and oncoming nurse to clarify information and answer questions, in presence of the patient [6]. Nurses may use standardized report templates as handoff tools [18]. In prior studies, there are several definitions used to describe change-of-shift report [6]. As context of this study is nurse-to-nurse bedside change-of-shift reporting, we adopt the definition employed by [23] and define shift reporting as a "...system of nurse-tonurse communication between shift changes intended to transfer essential information for safe, holistic care of patients...” (p.12).

While there are research studies that report on the various types of handoff, to the best of our knowledge, very few studies have examined how technology (EMR) has supported or improved verbal face-to-face reporting at the patient's bedside. The current research is an exploratory study to understand what issues exist when nurses assisted by an EMR exchange information, verbally in inpatient settings. Specifically the study explores (a) how computerized patient record (or an EMR) facilitates bedside reporting at the time of shift change (b) given an EMR is not fully integrated 
into the bedside reporting process, how can the process in itself be improved (c) in general, how can the process of bedside shift reporting be improved.

The paper is structured as follows. We begin by discussing relevant literature on change-of-shift reporting. Next, we describe in detail the current shift reporting process followed at the hospital, the site of the current study. Subsequently, we explain the methodology used to collect and analyze the qualitative data and present the findings. Finally, we outline recommendations and discuss limitations and future research directions.

\section{Prior Research}

Regardless of the method used, nurse change-ofshift report usually takes place at a designated time; at the end of the shift nursing staff communicate to the oncoming shift updated information about each patient's condition, symptoms, treatment, results, medications, and responses to treatment plan and interventions [28]. In addition, handoff report provides an opportunity for the nurses to transfer responsibility and to ensure continuity of care [24]. Change-of-shift reporting is crucial to providing patients the proper treatment, assuring patient safety [12, 26, 27]. Further, efficient time management during the handoff process enables nurses to engage in direct patient care and reduce end-of-shift overtime [5].

Prior research [for example, 1, 2] suggests that primary problems with change-of-shift reports include communication barriers and a systematized handoff process. Some [for example, 27, 28, 30] suggest that electronic handoffs reduce communication errors and improve efficiency during shift change; however, others [for example, 10, 24] argue that substituting face-to-face handoffs with electronic records impede nurse workflow and care coordination, during shift change. Some studies [for example, 16] have shown that nurses rely on informal, hand-written, personalized paper forms even in facilities with an EMR with full range of capabilities.

In summary, evidence from extant research suggests that there may not be one method of handoff that ensures error 'free' exchange of information. In this study, technology supported verbal reporting challenges are examined. The following section discusses in detail the face-to-face bedside shift reporting process followed at the hospital, highlighting the sources and methods used to exchange information.

\section{Background}

In the inpatient setting, verbal nurse shift report handover between the outgoing and incoming nurses must incorporate all critical information about a patient's plan of care and health status. Nurses should correctly and efficiently communicate information during the face-to-face exchange [11]. This enables effective coordination and continuity of care transition [20].

At present, in most units throughout the hospital where this study was conducted, nurses work one of two shifts; day-shift from $7 \mathrm{am}$ to $7 \mathrm{pm}$, or night-shift, from $7 \mathrm{pm}$ to $7 \mathrm{am}$. Handoff, or bedside report handover between nurses, takes place at the patient's bedside at $7 \mathrm{am}$ and $7 \mathrm{pm}$. The on duty (or outgoing) nurse typically gives a verbal in-person shift report to the incoming nurse at the patient's bedside. Nurses use the EMR, patient worksheet (with pre-printed information that originates from data stored in the EMR), and selfassessed patient data, to assist in the preparation for each shift report/handoff.

\subsection{Electronic Medical Record (EMR)}

The EMR is updated continuously. Every time an on duty (outgoing) nurse performs an assessment, intervention, vital signs, or gives medication, she completes the documentation of that activity in the EMR. The on duty (outgoing) nurse would use the EMR to gather and verify the information about the patient for the bedside report. For example, a nurse would use the data in the EMR to review patient's vital signs for the shift, check for critical laboratory values, test, or procedure results, review the patient's history and see what orders the physician has entered. The nurse may also verify what orders were completed and compare it to the ones that are outstanding, by referencing the relevant information in the EMR.

\subsection{Patient Worksheet/Pre-printed Report}

In most units (example Medical-surgical, Oncology, Telemetry) at the hospital, the patient worksheet (pre-printed report) is a single-page paperbased template. The information pre-printed on the patient worksheet originates from the data available in the EMR. The information pertains to patient demographic data (for example, full name of the patient, date of birth), date of admission, name of the attending physician, patient's location, allergies, and recent physician orders. The information in the worksheet is not updated frequently (for example, medication orders that were outdated show up on the worksheet even after a few days). 
The patient worksheet is also used by majority of the nurses to handwrite personal notes (at the bottom of the patient worksheet), while the face-to-face interactions during bedside shift reporting take place. In the Intensive Care Unit (ICUs) settings at the hospital, the patient worksheet is referred to as Cardex. In contrast with the non-acute areas, the Cardex used in the ICUs for handoff is manually updated each shift, remains at the patient's bedside and contains the most up to date information.

\subsection{Nurse's Assessment of Patient Data}

The on duty nurse's personal observation of the patient during the course of the shift constitutes some components of the patient information recorded by her during course of the shift. This information primarily comprises of what was observed about the patient (such as, how was the patient responding to treatment or plan of care) during the shift.

In order to keep record of the information exchanged, incoming nurses typically store information received during handoff in the following ways: (a) enter own personal handwritten notes at the bottom of the patient worksheet and (b) maintain a self-prepared form that was created by an individual nurse to keep herself organized throughout the duration of the shift. These 'self" prepared worksheets or forms are organized in a manner that makes sense to the nurse, keeping her workflow in mind. Some nurses may not handwrite any information, choosing to purely rely on their memory or use the EMR to keep them on 'track'.

The offgoing nurse uses information gathered from (a) EMR (b) the patient worksheet (or pre-printed report coming from information available in the EMR) (c) patient assessment data, to verbally transfer or communicate information to the incoming nurse. Typically, the incoming nurse records information obtained during the verbal exchange based on her personal preferences.

The hospital had recognized inadequacies in the bedside change-of-shift reporting process. An inefficient and non-standardized handoff process affects care coordination, nurse workflow, patient safety, and clinical outcomes. The nurses were also unable to leave on time, creating financial consequences for the hospital's unit related to end-ofshift overtime. The hospital leadership's priority has always been of continuous improvement. One of their leading initiatives was to enhance and optimize the current bedside shift reporting process. Our research team collaborated with hospital's administration and employees to conduct this study. The focus was to identify specific issues in the bedside reporting process and provide recommendations for its improvement.

\section{Methods}

Qualitative content and thematic analysis was used with the data from audio-recordings of interviews with registered nurses (RNs). The focus was on the description and interpretation of nurses' perspectives about preparation for the bedside shift reporting process using the EMR [29]. Approvals were obtained from the University (to which some of the authors were affiliated), and the hospital's institutional review board, and hospital administration, prior to data collection.

\subsection{Setting}

The current study was conducted at a hospital 431bed acute care hospital located in the Southeast region of Texas, as a part of a larger study undertaken to improve patient outcomes. The hospital is affiliated with a large non-profit corporation, and is recognized as a high-quality health care provider in the region. The hospital employs over 900 RNs.

\subsection{Sample}

Sixteen RNs from various units (including Telemetry, Oncology, and Medical-Surgical) as well as the ICU participated in the study. All RNs providing direct patient care received invitations to participate. Participation in the study was voluntary. The hospital offered participants credit toward their career ladder program and a gift card (\$5 value), as incentives.

\subsection{Data Collection}

Nurses at the hospital's units worked 12-hour shifts, with nurse shift report handoffs scheduled twice within a period of twenty-four hours - at 7am and 7pm. Nurses participating in the study were asked to compile a shift report on a simulated patient case, just as if they would do for a 'real' patient during shift change. The process on the computer was videotaped while participants were accessing the EMR. However, the faces of the nurses were not videotaped, to conceal their identity and maintain confidentiality.

Subsequently, with this same cohort of nurses, interviews were conducted asking open-ended questions about their experiences and perceptions regarding the bedside shift report process and the EMR they used during the process. Open-ended questions included (1) What are the general concerns regarding the way bedside shift report is currently generated? (2) 
What works well with the computerized patient records /EMR when preparing for bedside shift report? (3) What does not work well with the EMR when preparing for bedside shift report? (4) What can be automated to decrease time when giving report and receiving reports? (5) Are there any additional inputs to improve the EMR used for bedside shift report? (6) What additional tools/technology can be helpful in assisting bedside shift reporting? All interviews were audiotaped. After the conclusion of the sixteen interviews, each nurse was asked to fill out a brief demographic survey.

\subsection{Data Analysis}

Audiotaped RN interviews were transcribed wordfor-word and verified by two of the authors for accuracy. Only one of the authors who interviewed the RNs knew the names of the participants and their code numbers to protect the identities of subjects participating in the study. The transcribed interviews were analyzed to understand nurses' use of the EMR during bedside shift report preparation and nurses' general perceptions about the process using conventional content analysis techniques prescribed in prior research [13, 29].

The three (out of the five) authors worked jointly as well as independently with the analysis of the interview transcripts, moving back and forth among them. The three authors analyzed six of the sixteen transcripts jointly. The first six were analyzed by all authors to develop the themes and sub-themes. The remaining manuscripts were then analyzed independently by the three authors (KG, EDC and MEG) using the jointly developed coding manual consisting of ten themes. Few examples of themes included: Missing Patient Worksheet Information, Outdated Patient Information, Standardization, Distrust, and Customized Information. Two of the transcripts were compared for reliability and validity of coding across raters. The analysis revealed similar themes and meaning across the three authors.

\section{Results}

The sample consisted of one male and fifteen female RNs. The majority (75\%) of the RNs were thirty-five years or older. In terms of education level, one had a Master's degree in nursing while the remaining nurses had earned a Bachelor's in nursing. Further, six nurses had obtained an advanced certification in nursing. Nurses' experience at the hospital ranged from four months to forty years, with an average of approximately eleven years. Total nursing experience (as RNs) ranged between one month to thirty-eight years, with an average experience of 15.7 years.

Nurse interviews revealed that the end-of-shift face-to-face report consisted of several steps or subprocesses. These steps included content transfer (sharing patient information) between outgoing and incoming nurse; clarification and inquiry (asking and answering questions relevant to patients condition); and reviewing patient history (EMR charts and notes). Consistent with handoffs described in prior research [31], there was some degree of overlap among these steps during the shift report process.

Further, nurses indicated that they added pertinent information (for example, important laboratory results, activities to complete, list of medications due) to the pre-printed report throughout their shift. Nurses mentioned that they relied more on their assessment of the patient's condition, rather than the information in the pre-printed report. They used the EMR primarily to enter additional information (handwritten notes) in the pre-printed report about the patient's condition as well as verify information such as intake and output volumes, vital signs, physician orders or a recent pain medication. Table 1 presents the themes and relevant concepts described in prior research.

\subsection{Quality and Content of Information}

For improved care coordination, nurses receiving report needed the following - patient's reason for admission, existing problems of the patient, patient's relevant medical history, recent lab work, radiology results, information about the patient's medication, Intravenous information, necessary nursing interventions, and the most recent physician orders.

Nurses suggested that the information provided in the pre-printed report was unreliable (outdated information), since majority of patient information was not updated throughout the patient's hospital stay. This could be attributed to inadequate information processing [8]. Transfer of information may have been inaccurate due to information overload, sometimesambiguous language, use of different technical/clinical jargons among nurses, and differences in work styles $[16,19]$. As one nurse remarked, "the information on the bottom [of patient worksheet] is not current because we don't go through it and kind of delete things...so you get stuff [patient information] stacked from when they [patient] were admitted the first day." (Interviewee 13)

Nurses as reasons for being transferred missing patient worksheet information, cited certain cultural norms and values that developed into accepted behavior over the course of time working at the hospital [19]. Nurses revealed that since multiple 
sources (EMR, pre-printed report, and nurse's own assessment of patient' data) were being used to create the bedside report, the information, was sometimes missing critical components. As one nurse indicated, "Unless somebody puts, you know some of the posts underneath like you know what was the result of chest $x$-rays you know or sometimes wound care can slide a little bit unless you know the patient " (Interviewee 16)

Nurses suggested that at times, they did not trust the information passed to them by the outgoing nurse or the information provided in the pre-printed report. This could be due to incorrect framing of problems/risks and solutions (resilience) initiated due to certain individual assumptions (regarding patient's condition) made by an individual nurse [8]. As one nurse noted, “...after I receive report, I usually have the habit of going and checking over everything anyways. So even if I got a copy with everything in there... I do not know I will use it. Of course its relevant information, but I don't know that I will completely trust on that." (Interviewee 11)

Nurses preferred to work with the pre-printed report that had customized (specific to the unit as well as the patient) information available. They indicated that each unit had its specific need (depending on the type of care required, such as for an oncology patient as opposed to a surgery patient), and every patient was different. Hence, it would be more efficient to obtain information that was tailored to suit the needs of a unit and/or take care of the particular needs of a patient needs. Thus, pre-printed reports should be adaptive and tailored to both the patient's diagnosis and condition, as well as individual nurses’ preferences [27]. The idea of stereotypical narratives [19] could be linked to this. It proposes that appropriate patient narrative should be inextricably attached to handoff reports; caregivers or nurses should not apply default assumptions regarding patient condition. As one nurse remarked: "I think it [information] needs to be more uniform in the sense that you know we [nurses] all have specific things on our bedside shift report whereas you know one nurse thinks this is important and the other one thinks it's important. So, there is just a variety of different things you get from nurses, because like on our unit you know we have a lot of surgery patients so knowing their last family name is really important.” (Interviewee 15)

\subsection{Process Related Inadequacies}

Nurses suggested that standardization of the patient worksheet (pre-printed report) would facilitate the handoff process. Interview transcripts referred to standardizing the handoff [4] and the pre-printed worksheet. As well, nurses suggested creating a process map and a standard checklist [4]. A relevant framework to associate standardizing handoffs is accountability [19], which refers to the notion of tracking tasks completed (or not), and tracing tasks that have been transferred (or not) to the incoming nurse. As one nurse remarked, "I think the report should be traditionally given nurse to nurse and all your questions answered and then have a set routine that's the same every time that you're going to do in the room” (Interviewee 10)

Current bedside reporting practices were time consuming [22]. This was primarily due to lack of standardization of the process itself, and issues with technology (for example, nurses not having access to computers, computer downtime). As one nurse commented, "It's a little time consuming. To go to do it how we're supposed to do it, where we do the whole history and the whole patient scenario in the patients room.... If we could have that worksheet and kind of look over the basic facts and then go in... I think that would kind of narrow the time frame a little” (Interviewee 13)

Nurses expressed apprehensions that the current bedside reporting process led to confidentiality concerns [14]. Specifically, conducting bedside reporting in the presence of the patients themselves, and/or the patients' family members could lead to privacy issues, as suggested by one nurse, "I don't think it's a good idea to say everything in front of the patient. And a lot of times too when nurses are talking to each other, they say something just kind of in that nurse lingo or medical lingo and the patient hears a piece of it and they grab hold of it and then it causes all kinds of anxiety " (Interviewee 10). Another nurse commented, "You know like if I guess it's you know we have like at the bedside and some of the people [family members of the patient] could overhear what you're talking about to serve. And I think that's a violation for the HIPAA..." (Interviewee 21)

\subsection{Issues Attributed to Technology}

Technology must be able to support coordination activities concurrently during bedside reporting [26]. However, as suggested by nurse interviews, the EMR was not as useful in the shift report process. Nurses needed to access multiple screens available in the EMR to gather information. Further, lack of automated compiling of patient worksheet data from EMR impeded their workflow. Nurses were not satisfied using unwieldly computers on wheels when moving from one patient bed to another (or from one patient room to the other). Instead, they preferred to use mobile/handheld devices [26]. In addition, some typical issues with technology (such as computer downtime) posed problems during handoffs. 
Table 1. Themes and Concepts

\begin{tabular}{|c|c|c|}
\hline Theme & Relevant Concept & Reference \\
\hline $\begin{array}{l}\text { Missing Patient } \\
\text { Worksheet } \\
\text { Information }\end{array}$ & $\begin{array}{l}\text { Inadequate } \\
\text { information processing } \\
\text { (information omission) }\end{array}$ & [8], [19] \\
\hline $\begin{array}{l}\text { Outdated Patient } \\
\text { Information }\end{array}$ & $\begin{array}{l}\text { Cultural norms and } \\
\text { values that develop } \\
\text { over time to become } \\
\text { accepted behaviors }\end{array}$ & [19] \\
\hline Distrust & $\begin{array}{l}\text { Resilience (incorrect } \\
\text { framing of } \\
\text { problems/risks and } \\
\text { solutions) }\end{array}$ & [8], [19] \\
\hline $\begin{array}{l}\text { Customized } \\
\text { Information }\end{array}$ & $\begin{array}{l}\text { Stereotypical } \\
\text { narratives }\end{array}$ & [8], [19] \\
\hline Standardization & $\begin{array}{ll}\text { Accountability } & \\
\text { (tracking } & \text { tasks } \\
\text { completed, } & \\
\text { information } & \\
\text { transferred) } & \end{array}$ & [19] \\
\hline $\begin{array}{l}\text { Bedside Shift } \\
\text { Reporting is } \\
\text { Time Consuming }\end{array}$ & $\begin{array}{l}\text { Constraints (typically } \\
\text { observed in context of } \\
\text { handoffs) }\end{array}$ & [22] \\
\hline $\begin{array}{l}\text { Considerations } \\
\text { of Bedside } \\
\text { Reporting }\end{array}$ & Information discretion & [14] \\
\hline $\begin{array}{l}\text { Automated } \\
\text { compiling of } \\
\text { patient } \\
\text { worksheet data } \\
\text { from EMR } \\
\end{array}$ & $\begin{array}{l}\text { Information } \\
\text { processing } \\
\text { (matching } \\
\text { workflow) }\end{array}$ & [8], [19] \\
\hline $\begin{array}{l}\text { Typical Issues } \\
\text { with Technology }\end{array}$ & $\begin{array}{l}\text { Information } \\
\text { processing } \\
\text { (affecting } \\
\text { workflow) } \\
\end{array}$ & [8], [19] \\
\hline $\begin{array}{l}\text { Smaller } \\
\text { Mobile/Handheld } \\
\text { Devices }\end{array}$ & $\begin{array}{l}\text { Information } \\
\text { processing } \\
\text { (matching } \\
\text { workflow) }\end{array}$ & [8], [19] \\
\hline
\end{tabular}

\section{Discussion}

Findings indicated problems with the content of the pre-printed report. Certain limitations in the EMR affected coordination of care and hindered workflow. The following paragraphs elaborate these challenges and discuss possible strategies to resolve them.

\subsection{Content and Structure of Shift Report}

Nurses emphasized that end-of-shift reports should have pertinent content. What is considered as pertinent varies by unit and by patient (for example, patient's clinical condition, physical state, and specific needs) [31]. This enables the report to be less predisposed to inclusion of excessive or unnecessary patient information [31].

The information from the pre-printed report was being used throughout the shift, rather than just while giving, or receiving a handoff. Hence, the initial design of this report was very critical. Once the content is identified, the structure of the report must be determined. A structured end-of-shift report can significantly reduce content omissions and redundancies. Both, too little content and too much content were identified in the present study as barriers to effective reports. Structured end-of-shift report template should follow the 'SBAR' framework [31]. 'Situation, Background, Assessment, Recommendation' framework was created for streamlining conversations between care providers. It is designed to highlight what pertinent patient information must be transferred to expedite effective communication among providers [15].

\subsection{Match Nurse Workflow}

Current pre-printed reports (obtained from EMR) did not provide "at a glance" information cues that nurses needed during handoffs. Nurse interviews suggested that to assimilate all information needed during shift report, they would have to 'comb' through multiple screens in the EMR. Although, some of this information would be on the patient worksheet (preprinted report), it was not up to date since it was not automatically updated with the information in the EMR. A nurse would have to manually enter information to update the pre-printed report.

An improved EMR used during verbal bedside shift reporting must afford nurses with the information they need in an 'instant'. They should come with a feature to update information in the pre-printed reports on a real-time and automated basis. A tool to scan EMR for key patient information, which could then be extracted into a separate highlighted document for oncoming caregivers, could be very effective [25]. Further, an interface, that displays trends in data tailored to a specific patient [27], would help nurses to identify any abnormalities related to the patient's condition. These features in the EMR and additional technology tools would enable improvement of nurse workflow [25, 26].

\subsection{Shared Mental Models}

Nursing handoffs are activities that require nurses to perform information synthesis [26] across multiple information sources (in this case, EMR, pre-printed 
report, self-assessed patient data). As interviews suggested, the current EMR did not completely support the cognitive work of nurses during bedside shift reporting at various units in the hospital studied. Perhaps, the bedside reporting process could be more effective if nurses share mental models [25]. A mental model is the picture (or holistic view) an individual (nurse) has in their head of what is going on (with the patient). Prior research [for example, 22] suggests that effective mental models are developed when individual care providers focus on the (patient's) problem at hand, patient history, current clinical and physical state of the patient, and the critical needs of the patient [25]. Nurses involved in the handoff may view the patient's condition from different perspectives. However, to work effectively together, sharing a mental model may facilitate proper assessment of the myriad information available to them.

\section{Conclusions}

The findings are a call-to-action to focus attention on designing handoff forms/pre-printed reports that reduce nurses' cognitive 'burden; in particular, research should focus on data and information 'elements' to be included in the pre-printed report that suit the specific needs of nurses based on the unit they are assigned and the individual needs of their patients.

This study lays the foundations for future research to establish ways to create shared mental models for care providers involved in technology supported bedside reporting. Specifically, researchers could examine strategies to develop technologies assisting handoffs that allow care providers to establish shared mental models. Further, studies could identify technologies that help mitigate the challenges related to coordination during change-of-shift. It may be a valued proposition for future research to consider the effectiveness of electronic tools that automatically extract or 'pull' real-time information from the EMR into the pre-printed report, such as the one used by nurses in this study - do these supplementary tools enhance clinical workflow.

The current study is an attempt to understand the issues that cause inefficiencies in the bedside reporting process in various units of one hospital. Given the contextual nature of the change-of-shift reporting process, the findings of this study may not be applicable across other similar settings. Perhaps, data from other sites (hospitals) may reveal additional insights. Further, the authors conducted the qualitative analysis of the interview transcripts and qualitative data analysis tools (for example NVIVO) were not used. The authors plan to conduct further examination of the interview data using NVIVO prior to the conference.

\section{References}

[1] J. Abraham, V. Nguyen, K. F. Almoosa, B. Patel, and V. V. Patel. "Falling through the cracks: information breakdowns in critical care handoff communication", In AMIA Annual Symp Proc, 2011, pp. 28-37

[2] J. Abraham, T.G. Kannampallil, and V.L. Patel. "Towards an ontology for interdisciplinary handoff communication in intensive care: implications for tool resiliency and patient safety", In Proceedings of the International Symposium on Human Factors and Ergonomics in Health Care , Vol. 3, No. 1, 2014, pp. 196-202. Sage India: New Delhi, India: SAGE Publications.

[3] J. Abraham, T. Kannampallil, and V.L.Patel. “A systematic review of the literature on the evaluation of handoff tools: implications for research and practice", Journal of the American Medical Informatics Association, 2014, 21(1), pp.154-162.

[4] V. Arora and J. Johnson. "A model for building a standardized hand-off protocol”, The Joint Commission Journal on Quality and Patient Safety, 2006, 32(11), pp.646655.

[5] JA. Bernstein, D.L. Imler, P. Sharek, and C.A. Longhurst, "Improved physician work flow after integrating sign-out notes into the electronic medical record" The joint commission journal on quality and patient safety, 2010, 36(2), pp.72-AP2

[6] E.M. Caruso The evolution of nurse-to-nurse bedside report on a medical-surgical cardiology unit. Medsurg Nursing, 2007, 16(1), p.17.

[7] L.P.A.D. Cheah, and D.H. Amott, J. Pollard, and D.A. Watters, "Electronic medical handover: towards safer medical care”, Medical Journal of Australia, 2005, 183(7), p.369.

[8] D.S. Cheung, J.J. Kelly, C. Beach, R.P. Berkeley, R.A. Bitterman, R.I. Broida, W.C. Dalsey, H.L. Farley, D.C. Fuller, D.J. Garvey, and K.M. Klauer, "Improving handoffs in the emergency department”, Annals of Emergency Medicine, 2010, 55(2), pp.171-180.

[9] K. Chung, I. Davis, S. Moughrabi, and A. Gawlinski, "Use of an evidence-based shift report tool to improve nurses' communication”, MedSurg Nursing, 2011, 20(5), pp.255.

[10] J. Engesmo, and A.H. Tjora, "Documenting for whom? A symbolic interactionist analysis of technologically induced changes of nursing handovers", New Technology, Work and Employment, 2006, 21(2), pp.176-189. 
[11] M.E. Flanagan, E.S. Patterson, R.M. Frankel, and B.N. Doebbeling, "Evaluation of a physician informatics tool to improve patient handoffs", Journal of the American Medical Informatics Association, 2009, 16(4), pp.509-515.

[12] D. Flemming, and U. Hübner, "How to improve change of shift handovers and collaborative grounding and what role does the electronic patient record system play? Results of a systematic literature review", International journal of medical informatics, 2013, 82(7), pp.580-592

[13] U.H. Graneheim, and B. Lundman, "Qualitative content analysis in nursing research: concepts, procedures and measures to achieve trustworthiness”, Nurse Education Today, 2004, 24(2), pp.105-112.

[14] S. Gregory, D. Tan, M. Tilrico, N. Edwardson, and L. Gamm, "Bedside shift reports: what does the evidence say?" Journal of Nursing Administration, 2014, 44(10), pp.541545.

[15] E. Joffe, J.P. Turley, K.O Hwang, T.R. Johnson, T.R., Johnson, and E.V. Bernstam, "Evaluation of a problemspecific SBAR tool to improve after-hours nurse-physician phone communication: a randomized trial", The Joint Commission Journal on Quality and Patient Safety, 2013, 39(11), pp.495-AP6.

[16] D. Lamond, "The information content of the nurse change of shift report: a comparative study", Journal of Advanced Nursing, 2000, 31(4), pp.794-804.

[17] M.A. Makary, and M. Daniel, "Medical error-the third leading cause of death in the US”, BMJ: British Medical Journal (Online), 2016, 353.

[18] A.B. Nelson, and R. Massey. "Implementing an electronic change-of-shift report using transforming care at the bedside processes and methods." Journal of Nursing Administration, 2010, 40(4), pp. 162-168.

[19] E.S. Patterson, E.M. Roth, D.D. Woods, R. Chow, and J.O. Gomes, "Handoff strategies in settings with high consequences for failure: lessons for health care operations. International Journal for Quality in Health Care, 2004, 16(2), pp.125-132.

[20] S.S. Phillippe, "Care Coordination and Handoff for the Pediatric Patient in the Radiology Environment", Journal of Radiology Nursing, 2017, 36(1), pp.59-62.

[21] R. Randell, S. Wilson, S. and P. Woodward, "The importance of the verbal shift handover report: a multi-site case study", International journal of medical informatics, 2011, 80(11), pp.803-812.

[22] L.A. Riesenberg, J. Leisch, J. and J.M. Cunningham, "Nursing handoffs: a systematic review of the literature", The American Journal of Nursing, 2010, 110(4), pp.24-34.
[23] B. Riegel, "A method of giving intershift report based on a conceptual model” Focus on Critical Care, 1985, 12(4), pp.12

[24] J.J. Saleem, A.L. Russ, C.F. Justice, H. Hagg, P.R. Ebright, P.A. Woodbridge, and B.N. Doebbeling, "Exploring the persistence of paper with the electronic health record", International journal of medical informatics, 2009, 78(9), pp.618-628.

[25] A.J. Schoenfeld, and R.M. Wachter, "The Search for Better Patient Handoff Tools”, JAMA Internal Medicine, 2016, 176(9), pp.1402-1403.

[26] N. Staggers, and B.M. Jennings, "The content and context of change of shift report on medical and surgical units”, Journal of Nursing Administration, 2009, 39(9), pp.393-398.

[27] N. Staggers, L. Clark, J.W. Blaz, and S. Kapsandoy, "Why patient summaries in electronic health records do not provide the cognitive support necessary for nurses' handoffs on medical and surgical units: insights from interviews and observation", Health Informatics Journal, 2011, 17(3), pp.209-223.

[28] B. Strople, and P. Ottani, "Can technology improve intershift report? What the research reveals", Journal of Professional Nursing, 2006, 22(3), pp.197-204.

[29] M. Vaismoradi, J. Jones, H. Turunen, and S. Snelgrove, "Theme development in qualitative content analysis and thematic analysis”, Journal of Nursing Education and Practice, 2016, 6(5), pp.100.

[30] D.K. Vawdrey, D.M. Stein, M.R. Fred, S.B. Bostwick, and P.D. Stetson, "Implementation of a computerized patient handoff application”, In AMIA Annual Symposium Proceedings (Vol. 2013, p. 1395). American Medical Informatics Association, 2013.

[31] C.A. Welsh, M.E Flanagan, and P.Ebright, "Barriers and facilitators to nursing handoffs: Recommendations for redesign”, Nursing Outlook, 2010, 58(3), pp.148-154.

[32] M.V. Wohlauer, K.O. Rove, T.J. Pshak, C.D. Raeburn, E.E. Moore, C. Chenoweth, A. Srivastava, J. Pell, R.B. Meacham, and M.R. Nehler, "The computerized rounding report: implementation of a model system to support transitions of care”, Journal of Surgical Research, 172(1), pp.11-17. 